\title{
Hand grip strength and maximum peak expiratory flow: determinants of bone mineral density of adolescent students
}

\author{
Marco Cossio-Bolaños ${ }^{1,2,3}$, Cynthia Lee-Andruske ${ }^{4}$, Miguel de Arruda ${ }^{1}$, Cristian Luarte-Rocha ${ }^{5}$, \\ Alejandro Almonacid-Fierro ${ }^{6}$ and Rossana Gómez-Campos ${ }^{6,1,3^{*}}$
}

\begin{abstract}
Background: Maintaining and building healthy bones during the lifetime requires a complicated interaction between a number of physiological and lifestyle factors. Our goal of this study was to analyze the association between hand grip strength and the maximum peak expiratory flow with bone mineral density and content in adolescent students.

Methods: The research team studied 1427 adolescent students of both sexes (750 males and 677 females) between the ages of 11.0 and 18.9 years in the Maule Region of Talca (Chile). Weight, standing height, sitting height, hand grip strength (HGS), and maximum peak expiratory flow (PEF) were measured. Furthermore, bone mineral density (BMD) and total body bone mineral content $(\mathrm{BMC})$ were determined by using the Dual-Energy $X$ Ray Absorptiometry (DXA). Hand grip strength and PEF were categorized in tertiles (lowest, middle, and highest). Linear regression was performed in steps to analyze the relationship between the variables. Differences between categories were determined through ANOVA.

Results: In males, the hand grip strength explained $18-19 \%$ of the BMD and $20-23 \%$ of the BMC. For the females, the percentage of variation occurred between 12 and $13 \%$ of the BMD and 17-18\% of the BMC. The variation of PEF for the males was observed as $33 \%$ of the BMD and $36 \%$ of the BMC. For the females, both the BMD and BMC showed a variation of 19\%. The HGS and PEF were divided into three categories (lowest, middle, and highest). In both cases, significant differences occurred in bone density health between the three categories.

Conclusions: In conclusion, the HGS and the PEF related positively to the bone density health of both sexes of adolescent students. The adolescents with poor values for hand grip strength and expiratory flow showed reduced values of BMD and BMC for the total body. Furthermore, the PEF had a greater influence on bone density health with respect to the HGS of the adolescents of both sexes.
\end{abstract}

Keywords: Biological maturation, Hand grip strength, Maximum expiratory flow, Bone density health, Adolescents

\section{Background}

It is well known that peak bone mass is acquired during childhood and adolescence. This may be a key determinant of bone health and future fracture risk during adulthood [1]. A number of primary factors are believed to affect it: genetics, hormonal health, calcium intake, physical activity [2], nutritional status, vitamin E deficiency, poor calcium

\footnotetext{
* Correspondence: rossaunicamp@gmail.com

${ }^{6}$ Universidad Autónoma de Chile, 5 Poniente, 1670 Talca, Chile

${ }^{1}$ Faculty of Physical Education, State University of Campinas, Campinas, Brazil Full list of author information is available at the end of the article
}

absorption, delayed puberty, corticosteroid use, and chronic lung diseases (cystic fibrosis) [3]. In this context, building and maintaining healthy bones during the lifetime requires a complicated interaction between a number of physiological and lifestyle factors. Therefore, the basis for bone health is created during childhood and adolescence [4].

In general, few studies have been carried out focusing on children and adolescents associating hand grip strength and maximum expiratory flow with bone density and bone mineral content $[5,6]$. However, a number of studies have been conducted examining the young 
and adults [7-11]. These have demonstrated that hand grip strength, maximum oxygen consumption, and maximum expiratory flow are associated with bone mineral density in adults. These research studies are based on the simultaneous increase and the equivalent capacity of a muscle group to execute a simultaneous contraction on the stabilizing muscles of the trunk and extremities [5]. Therefore, during normal activity, the increased reactionary forces that control the musculoskeletal system are associated with and justified by the mechanostat theory.

During the past decade, many individuals have experienced a reduction in participating in daily physical activities (for example, walking less, greater use of cars, escalators, and elevators). Additionally, the importance of physical education and participating in sports has diminished at school and at home [12]. Consequently, these factors may play a fundamental role in the deterioration of bone health, muscle strength, and lung functioning of adolescents.

Moreover, reputable evidence exists showing that children, adolescents, and active adults have greater BMD, and they have less risk of fractures than do their inactive peers $[13,14]$. Therefore, an adequate level of physical aptitude is an important contributor to bone density health, particularly, with regard to the mechanical action that promotes functional adaptation of bone [15].

Despite this, to date, few studies have been conducted examining the association between bone density health, hand grip strength, and peak expiratory flow in adolescent students. Furthermore, a systematic association could be shown between hand grip strength and maximum expiratory flow with BMD and BMC of adolescents. Thus, a reduction in respiratory function and a lower propensity for physical exercise [6] expressed in terms of strength could impair bone health in children and adolescents. Therefore, these findings examining these factors could provide relevant information about bone health for adolescents. Furthermore, adolescence is considered to be a critical stage for the acquisition of bone density [16]. During this stage, significant changes occur throughout the growth process. During biological maturation, bone density and bone mineral content must be accumulated since they can mitigate the effects and incidences of osteoporosis in the future. Therefore, to examine these factors, the objective of this study was to analyze the association of hand grip strength and maximum peak expiratory flow with the density and bone mineral content of Chilean adolescent students.

\section{Methods}

\section{Sample}

A descriptive correlational research study was developed. The sample studied consisted of 1427 adolescents of both sexes (750 males and 677 females) from the Maule Region from the city of Talca (Chile). Ages ranged from 11.0 to 18.9 years $(15.59 \pm 2.09$ years). The students recruited for the study were selected from 8 schools from the public education system from the Maule Region (Chile).

Students selected for the study were those attending required physical education classes (once a week for 60 min per session) and who did not smoke. Students eliminated from the study included those engaged in training or competing in sports clubs because of their high levels of physical fitness and activity. Others excluded included those with broken bones, fractures, or a recent bone fracture.

The experimental protocol was based on the Helsinki Declaration Accord (World Medical Association for $\mathrm{Hu}-$ man Subjects). In addition, the researchers obtained permission from the administration of the different schools and the ethics committee from the Universidad Autónoma de Chile. Before the study began, participants and parents were informed about the research objectives and procedures. All parents provided informed written consent authorizing their children to participate in the project.

\section{Procedures}

To calculate age, the student's date of birth and the evaluation date were used. Administrators from each school provided the information.

The anthropometric variables for the Dual-Energy XRay Absorptiometry scan, the evaluation of hand grip strength (HGS), and the Maximum Peak Expiratory Flow (PEF) were taken in a closed laboratory with temperatures between 20 to $24{ }^{\circ} \mathrm{C}$. All measurements were taken during the months of March to July of 2015.

Standing height was measured with a portable stadimeter (Seca Gmbh \& Co. KG, Hamburg, Germany) with a precision of $0.1 \mathrm{~mm}$ according to the Frankfurt Plan. Sitting height (celiac-trunk height) was taken using a wooden bench with a height of $50 \mathrm{~cm}$ with a measurement scale of 0 to $150 \mathrm{~cm}$ with a precision of $1 \mathrm{~mm}$. All students' anthropometric variables were measured barefoot with the least possible clothing (shirt and shorts). The body mass index (BMI) was calculated using the standard formula: body mass $(\mathrm{kg}) /$ height $^{2}(\mathrm{~m})$. Anthropometric variables were evaluated twice by three evaluators. The Technical Error of Measurement (TEM) for all of the anthropometric variables varied between 1.0 to $2.0 \%$.

The Dual-Energy X-Ray Absorptiometry (DXA) (Lunar Prodigy; General Electric, Fairfield, CT) was used for the total body scan. Following the suggested descriptions of Kelly, Berger, and Richardson [17] and the manufacturer's instructions, all measurements were taken by an experienced well trained technician. Before commencing the scanning process, the subject had to lie supine on 
their backs on the scanning platform. Arms and legs were extended parallel to the bed. Both ankles were tied together with a Velcro belt to ensure a standard position for the subjects. The BMD $\left(\mathrm{g} / \mathrm{cm}^{2}\right)$ and the BMC (g) of the entire body were measured in addition to the variables for the percentage of body fat (\% F), muscle mass $(\mathrm{kg})$, bone mass $(\mathrm{kg})$, and fat mass $(\mathrm{kg})$. To guarantee the reliability of the scan, the measurements were repeated right after the first ones were taken the same day for every tenth subject. The technical error of measurement (TEM) between intra-raters produced values of less than $1.5 \%$.

Biological maturation (somatic maturity status) was estimated by predicting years from attainment of age at peak height velocity. Age at peak height velocity reflects the age of maximum growth rate in stature during adolescence. Years from age at peak height velocity (APHV) were predicted for each child using sex-specific regression equations that included stature, sitting height, leg length, chronological age, and their interactions Mirwald et al. [18]. This method is simple, is non-invasive, and has demonstrated acceptable agreement when correlated against skeletal age $(r=0.83)$.

The equations used for boys included the predictive equation: Maturity Offset $=-9.236+0.0002708 *$ Leg Length and Sitting Height interaction - $0.001663 *$ Age and Leg Length interaction +0.007216 "Age and Sitting Height interaction $+0.02292 *$ Weight by Height ratio, where $R=0.94, \mathrm{R}^{2}=0.891$, and $\mathrm{SEE}=0.592$.

In girls, the predictive equation was Maturity Offset: $9.376+0.0001882$ *Leg Length and Sitting Height interaction +0.0022 "Age and Leg Length interaction + 0.005841 *Age and Sitting Height interaction - 0.002658*Age and Weight interaction +0.07693 "Weight by Height ratio, where $R=$ $0.94, R^{2}=0.890$, and SEE $=0.569$.

Evaluation of the Maximum Peak Expiratory Flow PEF (L/min) was conducted with the brand name device Mini Wright (Clement Clarke International Ltd., Essex, England) with a range of 60 to $900 \mathrm{~L} / \mathrm{min}$ [19]. The PEF was obtained by a forced exhalation maneuver beginning with a maximum inhalation (equal to a spirometric test). Following the directions of Quanjer et al. [20], subjects were evaluated in a standing position without bending the neck. Prior to the evaluation, the device was described to the adolescent subjects, and they were allowed to practice the exercise twice (familiarization). Afterwards, the assessment was carried out with the highest value recorded of the three attempts. The Technical Error of Measurement (TEM) was less than 2\% for both sexes. The PEF was classified as lowest (first tertile), middle (second tertile), and highest (third tertile).

Hand grip strength was measured with the aid of a manual hydraulic dynamometer label JAMAR (Hydraulic Hand Dynamometer ${ }^{\bullet}$ Model PC-5030 J1, Fred Sammons,
Inc., Burr Ridge, IL: USA) with $0.1 \mathrm{lbf}$ accuracy of both the right and left hands, following the protocol recommended by Richards et al. [21]. Each subject was seated in a straight-backed chair in the standard position. Then, each volunteer was asked to squeeze the dynamometer two times with each hand. To control for the effects of fatigue, trials on each hand alternated so that approximately 2-min rest lapsed between trials for each hand. The best value of two attempts was recorded. The inter-rater Technical Error of Measurement was less than 2.5\% for both hands. HGS was classified as lowest (first tertile), middle (second tertile), and highest (third tertile).

\section{Statistical analysis}

Data normality was verified using the KolgomorovSmirnov test corrected by Lilliefors, and the residue variance homogeneity was verified using the Levene test. Arithmetic descriptive statistics and the standard deviation were used to describe the variables in this study. The "t-test" of student for independent samples was used to verify the differences between the sexes. The Pearson coefficient was used to evaluate the association between the predictor variables and the dependent variables (BMD and BMC). Afterwards, linear regression analysis was performed in steps for biological maturation, hand grip strength, and maximum peak expiratory flow as the independent variables and BMD and BMC as dependent variables. Furthermore, to classify the PEF and HGS variables into categories of lowest, middle, and highest, tertiles were calculated. Differences between categories were determined through one-way ANOVA and Sheffé post hoc. In all of the cases, 0.05 was adopted as the level of significance. Statistical calculations were performed using Excel sheets and SPSS 18.0.

\section{Results}

The descriptive statistics values for the variables for both sexes in this study are presented in Table 1 below. Females reached somatic maturation (11.78 \pm 0.48 APHV) before the males (14.98 $\pm 0.93 \mathrm{APHV})$. Males were heavier, had a taller standing height, higher sitting height, greater $\%$ of fat, body fat, lean mass, total body BMD, total body BMC, isometric strength (right and left), and maximum peak expiratory flow in relation to the females $(p<0.001)$. No significant differences occurred in chronological age and BMI between both sexes $(p>0.001)$.

The linear regression analysis in step multiples (Tabla 2) demonstrated that the somatic maturation, left and right hand grip strength, and maximum peak expiratory flow variables were associated with the bone health (BMD and $\mathrm{BMC}$ ) of adolescent students of both sexes. The \% of explained variation was greater in males than females.

Figures 1 and 2 illustrate the significant differences in $\mathrm{BMD}$ and $\mathrm{BMC}$ based on the categories of PEF and hand 
Table 1 Characteristics of the sample studied

\begin{tabular}{|c|c|c|c|c|c|c|}
\hline \multirow[t]{2}{*}{ Variables } & \multicolumn{2}{|c|}{ Males $(n=750)$} & \multicolumn{2}{|c|}{ Females (677) } & \multicolumn{2}{|c|}{ Both sexes $(n=1427)$} \\
\hline & Mean & SD & Mean & SD & Mean & SD \\
\hline Age (years) & 15.67 & 2.04 & 15.45 & 2.18 & 15.59 & 2.09 \\
\hline Biological age (APHV) & 14.98 & 0.93 & 11.78 & $0.48^{*}$ & & \\
\hline \multicolumn{7}{|l|}{ Anthropometry } \\
\hline Weight (kg) & 64.81 & 14.86 & 58.67 & $12.52^{*}$ & 62.66 & 14.38 \\
\hline Standing height (cm) & 165.41 & 17.45 & 152.84 & $28.81^{*}$ & 160.92 & 22.98 \\
\hline Sitting height (cm) & 86.93 & 6.17 & 83.02 & $4.28^{*}$ & 85.59 & 5.89 \\
\hline $\mathrm{BMI}\left(\mathrm{kg} / \mathrm{m}^{2}\right)$ & 23.18 & 4.30 & 23.41 & 4.31 & 23.26 & 4.30 \\
\hline \multicolumn{7}{|l|}{ Body composition (DXA) } \\
\hline Percentage of Fat (\% G) & 23.99 & 8.49 & 34.94 & $7.37^{*}$ & 27.7 & 9.64 \\
\hline Fat Mass (kg) & 15.34 & 8.18 & 20.23 & $8.19^{*}$ & 17.01 & 8.50 \\
\hline Lean Mass (kg) & 46.76 & 9.92 & 36.2 & $6.85^{*}$ & 43.18 & 10.29 \\
\hline \multicolumn{7}{|l|}{$\mathrm{BMD}\left(\mathrm{g} / \mathrm{cm}^{2}\right)$} \\
\hline Body total & 1.051 & 0.160 & 0.941 & $0.110^{*}$ & 1.010 & 0.152 \\
\hline \multicolumn{7}{|l|}{ BMC (g) } \\
\hline Body total & 2.509 & 0.543 & 2.051 & $0.35^{*}$ & 2.348 & 0.532 \\
\hline \multicolumn{7}{|l|}{ Isometric strength (Ibf) } \\
\hline Right Hand & 65.27 & 30.24 & 50.03 & $19.19^{*}$ & 59.01 & 27.31 \\
\hline Left Hand & 62.84 & 28.84 & 46.95 & $17.69^{*}$ & 56.32 & 26.07 \\
\hline Maximum peak expiratory flow (L/min) & 368.89 & 119.37 & 296.35 & $82.86^{*}$ & 346.02 & 114.18 \\
\hline
\end{tabular}

$X$ Mean, SD Standard deviation, APHV Age at peak height velocity, BMI Body Mass Index, BMD Bone Mineral Density, BMC Bone Mineral Content, ${ }^{*}=$ Significant difference $(p<0.001)$

grip strength (lowest -first tertile, middle - second tertile, and highest third tertile). Differences occurred between the three categories and in both sexes for PEF and HGS. Furthermore, males showed greater BMD and BMC when compared to the females in all of the categories.

\section{Discussion}

The results of the research illustrate that the HGS is associated moderately to the BMD and BMC in adolescents of both sexes. These results point to a positive association between bone formation and hand grip strength in the arms. Therefore, in males, the HGS explains between 18 and $19 \%$ of the BMD and $20-23 \%$ of the $\mathrm{BMC}$ and in females, between 12 and $13 \%$ of the BMD and $17-18 \%$ of the BMC. These findings are consistent with those of other studies carried out on young athletes [22, 23], non-athletes [24, 25], and sedentary adults [26, 27] even though these research studies

Table 2 Estimation of the BMD and BMC predictors base $d$ on linear multiple regression of adolescent students

\begin{tabular}{|c|c|c|c|c|c|c|c|c|c|}
\hline \multirow{2}{*}{$\begin{array}{l}\text { Dependent } \\
\text { variables }\end{array}$} & \multirow[t]{2}{*}{ Independent variables } & \multicolumn{4}{|c|}{ Males } & \multicolumn{4}{|c|}{ Females } \\
\hline & & $\bar{R}$ & $R^{2}$ & EE & $p$ & $\bar{R}$ & $R^{2}$ & EE & $p$ \\
\hline \multicolumn{10}{|c|}{$\mathrm{BMD}\left(\mathrm{g} / \mathrm{cm}^{2}\right)$} \\
\hline \multirow[t]{4}{*}{ Body total } & Somatic Maturation & 0.73 & 0.53 & 0.11 & 0.00 & 0.60 & 0.36 & 0.08 & 0.00 \\
\hline & Hand grip strength - left & 0.44 & 0.19 & 0.14 & 0.00 & 0.35 & 0.12 & 0.10 & 0.00 \\
\hline & Hand grip strength - right & 0.43 & 0.18 & 0.14 & 0.00 & 0.36 & 0.13 & 0.10 & 0.00 \\
\hline & Maximum peak expiratory flow & 0.57 & 0.33 & 0.12 & 0.00 & 0.44 & 0.19 & 0.10 & 0.00 \\
\hline \multicolumn{10}{|l|}{ BMC (g) } \\
\hline \multirow[t]{4}{*}{ Body total } & Somatic Maturation & 0.79 & 0.62 & 0.31 & 0.00 & 0.64 & 0.41 & 0.24 & 0.00 \\
\hline & Hand grip strength - left & 0.49 & 0.24 & 0.44 & 0.00 & 0.41 & 0.17 & 0.27 & 0.00 \\
\hline & Hand grip strength - right & 0.48 & 0.23 & 0.45 & 0.00 & 0.43 & 0.18 & 0.27 & 0.00 \\
\hline & Maximum peak expiratory flow & 0.60 & 0.36 & 0.41 & 0.00 & 0.44 & 0.19 & 0.30 & 0.00 \\
\hline
\end{tabular}



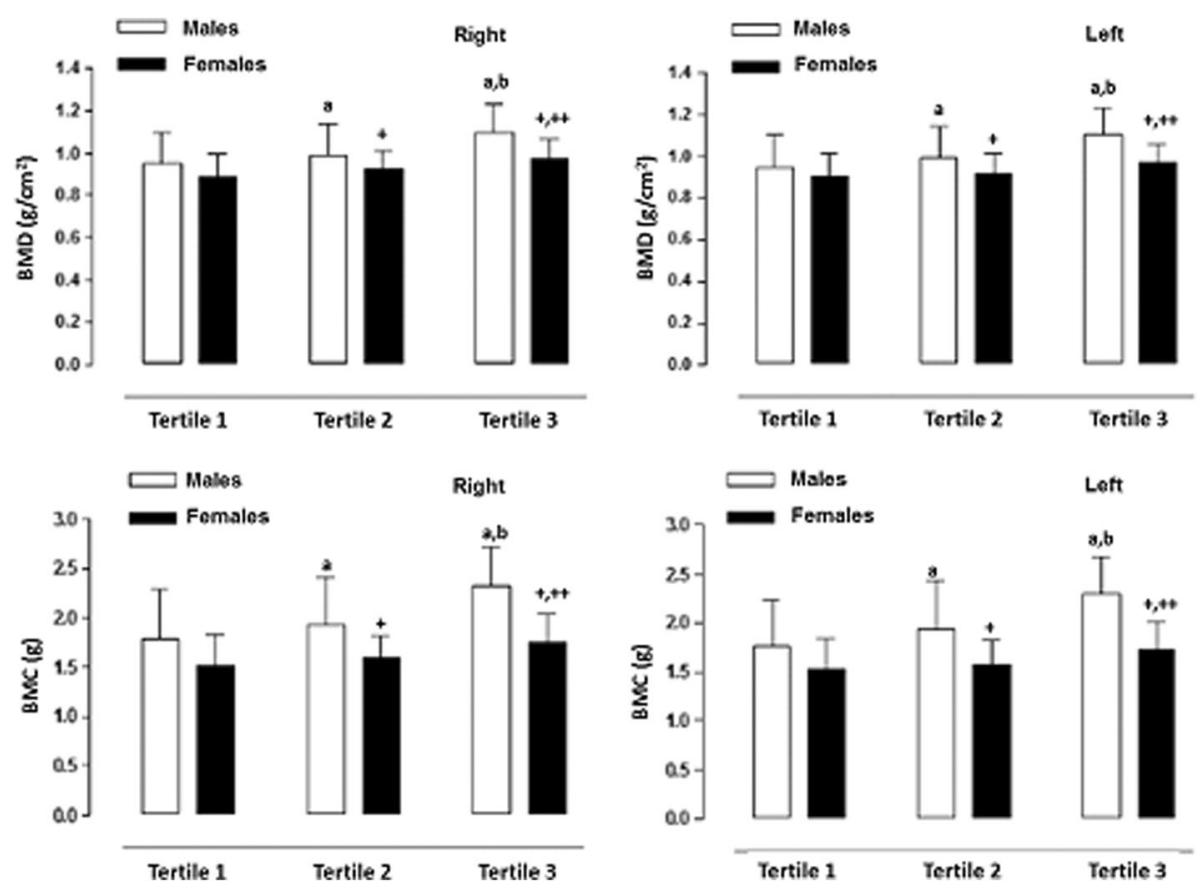

Fig. $1 \mathrm{BMD}$ and BMC values for adolescent students based on hand grip strength expressed in categories (tertiles). a: significant difference related to males in Tertile 1 ; b: significant difference related to males in Tertile $2 ;+$ : significant difference in females in Tertile $1 ;++$ : significant difference in females in Tertile 2

showed correlations slightly higher than those of this present study.

These results demonstrated that the PEF and the HGS independently predict bone health of this group of males and females. These systematic associations suggest that elevated levels of PEF and HGS produce a mediating effect over all the musculo-skeletal and respiratory systems. This could help promote better bone health.

The differences found in Fig. 1 are a clear illustration that the adolescents categorized here with low hand grip strength values demonstrated the lowest values in BMD and $\mathrm{BMC}$ in both sexes in relation to the other groups (middle and highest). In this sense, the weakness in the hand grip strength can be interpreted as bone fragility [28] in the total body. Moreover, it is associated with the loss of physical function and with a negative impact on recuperative health after an illness or surgery [29]. Furthermore, the adolescents in this study classified in the second tertile (middle) and the third tertile (highest) can be considered to have the maximum performance in hand grip strength and expiratory flow. This implies greater BMD and BMC values in both sexes.

These findings may be explained by the mechanostat theory since the bones adapt not only to static forces (of excessive weight) but also to the dynamic forces created by muscular contractions [30]. The differences in
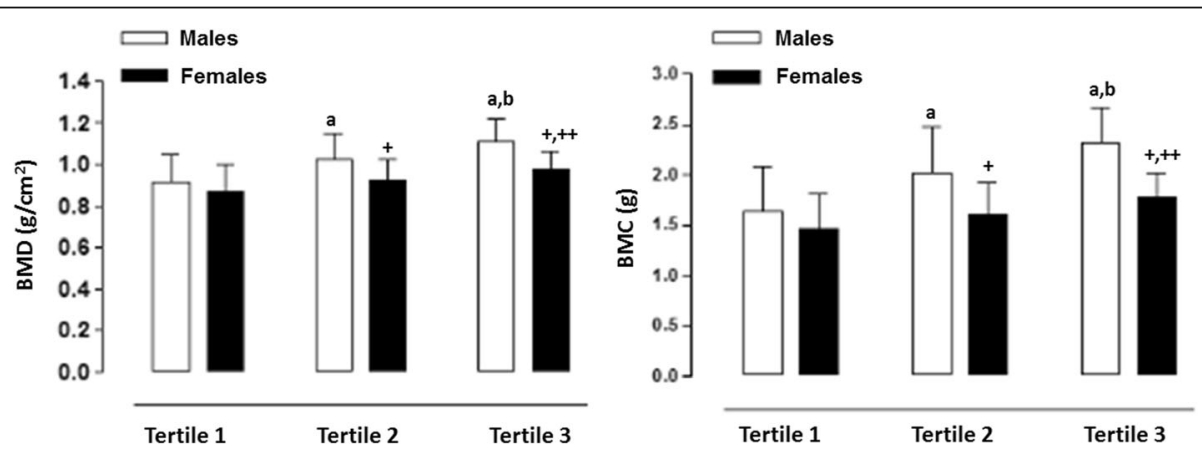

Fig. 2 BMD and BMC values of adolescent students based on maximum peak expiratory flow expressed in categories (tertiles). a: significant difference related to males in Tertile 1; b: significant difference related to males in Tertile 2; + : significant difference irelated to females in Tertile 1; ++ : significant difference related to females in Tertile 2 
strength observed in both sexes could be explained by a greater physical performance level in males. Additionally, males tend to have greater performance levels than do females during the same stage [31]. Furthermore, females may be at greater risk of developing bone fragility during adulthood as compared to males [32].

In general, hand grip strength is associated with, at least predicts to a certain extent, bone health in adolescents in both sexes. Additionally, it might be considered as a possible indicator of bone health since it is easy to use and non-invasive for measuring muscle strength in the arms [23]. Moreover, it is suitable for clinical use in epidemiological contexts.

With regard to the maximum peak expiratory flow (PEF), the results demonstrated a positive association to bone health in both sexes. In males, the $\mathrm{R}^{2}$ explains $33 \%$ of the variation in the BMD and $36 \%$ in the BMC. For females, the $\mathrm{R}^{2}$ explains $19 \%$ in both the BMD and BMC. In fact, in some previous studies, researchers have verified that a decrease in PEF correlates to a low BMD in children and adolescents with chronic obstructive pulmonary disease (COPD) [3, 33, 34]. These results a are consistent with studies carried out in adults without COPD $[10,11]$.

In essence, the adolescents of both sexes in this study categorized as having lowest expiratory flow (first tertile) showed reduced values in bone health. This can be attributed to greater resistance in the respiratory airways and the dysfunction of the respiratory muscles. Therefore, the restriction of the expiratory flow can limit participation in physical exercise [6]. Consequently, it affected the expiratory flow capacity in the adolescents in this study. Therefore, individuals with low levels could be susceptible to bone disorders, including the loss of BMD. As a result, these individuals are at greater risk of bone fractures [35]. Moreover, the males performed better in terms of maximum expiratory flow compared to the females. This illustrates that males showed a greater respiratory capacity than the females. The results suggest that females should improve their PFE by engaging in physical activities and participating in basic programs to improve muscle strength in physical education classes. In the long run, these appear to be valid strategies for reducing the number of falls and fractures [36].

The results from this research suggest that the greater the flow of air exhaled, the greater the lung capacity to carry out physical exercise. Therefore, childhood and adolescence are critical stages for solidifying the practice of physical activity. Studies suggest developing cardiopulmonary capacity $[37,38]$ and physical activity in general for improving bone health in children and adolescents. Furthermore, other studies have demonstrated that the expiratory flow is associated with good physical functioning, cognition, and mortality in adult subjects of an advanced age [39, 40]. However, it is important to reiterate that the association between lung functioning and BMD are complicated, and they are still not clear [41].

In essence, the practice of moderate physical activity, especially, strenuous activities that involve the support of body weight and the playing of sports, are important for promoting bone strength [42, 43]. Moreover, researchers suggest maximizing lung function to optimize bone health in adolescents.

In general, the PEF is one of the important parameters developed for evaluating lung function and for diagnosing, managing, and following respiratory diseases [44]. Moreover, its use and application is justified not only in children and adolescents with asthma but also with student populations without apparent pulmonary disorders.

It is important to point out that the present research has a few limitations. In the first place, the type of transversal study did not allow a causal association to be established. However, future studies need to include experimental and/or longitudinal research to establish causality between the variables examined. In the second place, the associations analyzed here are probably influenced by other intervening variables such as the quantity consumed of vitamin D and the cardio-pulmonary aptitude level. These variables were not available; however, if they would have been, they would have allowed us to discuss the results more effectively. On the other hand, with regard to the strength of the study, it is important to reiterate that the sample size was ample and representative of adolescent students participating. Moreover, the assessment of bone health by using the "Gold Standard": the DXA and the easy to access and easy to use devices (the manual dynamometer and the Mini Wright device). These are strong points of this study as is the control for biological maturation. These points make this study applicable to other student contexts.

\section{Conclusion}

In conclusion, the HGS and the PEF are associated positively to bone health of adolescent students of both sexes. The students with lowest hand grip strength and expiratory flow values showed lower values of BMD and BMC. Moreover, it is important to point out that the influence of the PEF is greater with regard to bone health with respect to muscle strength in the arms of adolescents. These results reinforce inclusion of physical exercise to improve lung functioning and muscle strength in adolescent students. However, more studies are needed focusing on adolescent students to confirm our findings.

\section{Abbreviations}

APHV: Age at peak height velocity; BMC: Body bone mineral content; BMD: Bone mineral density; BMI: Body Mass Index; DXA: Dual-Energy X-Ray Absorptiometry; HGS: Hand grip strength; PEF: Maximum peak expiratory flow; TEM: Technical error of measurement 


\section{Acknowledgements}

Not applicable.

\section{Funding}

We would like to express our thanks to all the participating students, teachers, and schools for their tremendous support. Supported by the Regular Fondecyt Project 1141295. Conicyt, Chile and internal project UA-048-17.

Availability of data and materials

The datasets supporting the conclusions of this article are available in the mail the corresponding author.

\section{Authors' contributions}

M.C.B., R.G.C. and M.A contributed to the design of the experiment. R.G.C., M.C.B., C.L.A. and M.A. researched data, contributed to the discussion, wrote the manuscript and reviewed/edited the manuscript. M.C.B., R.G.C., C.A., C.L.R., A.A.F., and M.A. researched data and/or reviewed/edited the manuscript. R.G.C., and M.C.B. provided statistical analyses and reviewed/edited the manuscript. All authors revised and agreed on the views expressed in the manuscript.

\section{Ethics approval and consent to participate}

The study protocol was approved by the Ethic Committee of the Universidad Autonoma de Chile, UA 238/2014. Parents and guardians provided informed written consent for their children under the age of 16 participating in the study. In addition, all students under and over the age of 16 in the study also provided written informed consent acknowledging their consent to participate understanding of the research procedures and objectives.

\section{Consent for publication}

Not applicable.

\section{Competing interests}

The authors declare that they have no competing interests.

\section{Publisher's Note}

Springer Nature remains neutral with regard to jurisdictional claims in published maps and institutional affiliations.

\section{Author details}

${ }^{1}$ Faculty of Physical Education, State University of Campinas, Campinas, Brazil. ${ }^{2}$ Departamento de Ciencias de la Actividad Física, Universidad Católica del Maule, Talca, Chile. ${ }^{3}$ Universidad Nacional de San Agustín, Arequipa, Peru. ${ }^{4}$ Red Iberoamericana de Investigación en Desarrollo Biológico Humano, Arequipa, Peru. ${ }^{5}$ Facultad de Ciencias de la Educación, Universidad San Sebastián, Concepción, Chile. ' Universidad Autónoma de Chile, 5 Poniente, 1670 Talca, Chile.

Received: 31 May 2016 Accepted: 28 January 2018

Published online: 02 March 2018

\section{References}

1. Rizzoli R, Bianchi ML, Garabedian M, McKay HA, Moreno LA. Maximizing bone mineral mass gain during growth for the prevention of fractures in the adolescents and the elderly. Bone. 2010;46:294-305.

2. Lehtonen-Veromaa M, Mottonen T, Nuotio I, Heinonen OJ, Viikari J. Influence of physical activity on ultrasound an dual-energy $\mathrm{x}$-ray absorptiometry bone measurements in peripubertal girls: a crosssectional study. Calcif Tissue Int. 2000;66:248-54.

3. Buntain HM, Greer RM, Schluter PJ, Wong JCH, Batch JA, Potter JM, Lewindon PJ, Powell E, Wainwright E, Bel SC. Bone mineral density in Australian children, adolescents and adults with cystic fibrosis: a controlled cross sectional study. Thorax. 2004;59:149-55.

4. Gordon CM. Evaluation of bone density in children. Current opinion in endocrinology, diabetes and Obesity. 2005;12(6):444-51.

5. Chan DCC, Lee WTL, Lo DHS, Leung JC, Kwok AWL, Leung PC. Relationship between grip strength and bone mineral density in healthy Hong Kong adolescents. Osteoporos Int. 2008;19:1485-95.
6. Legroux-Gérot I, Leroy S, Prudhomme C, Perez T, Flipo RM, Wallaert B, et al. Bone loss in adults with cystic fibrosis: prevalence, associated factors, and usefulness of biological markers. Joint Bone Spine. 2012;79:73-7.

7. Chilibeck PD, Sale GD, Webber CE. Exercise and bone mineral density. Sports Med. 1995;19:103-22.

8. Emslander HC, Sinaki M, Muhs JM, Chao EY, Wahner HW, Bryant SC, Riggs BL, Eastell R. Bone mass and muscle strength in female college athletes (runner and swimmers). Mayo Clin Proc. 1998;73:1151-60.

9. Petterson U, Nordstrom P, Lorentzon R. A comparison of bone mineral density and muscle strength in young male adults with different exercise level. Calcif Tissue Int. 1999;64:490-8.

10. Lekamwasam S, Trivedi DP, Khaw KT. An association between respiratory function and bone mineral density in women from the general community: a cross sectional study. Osteoporos Int. 2002;13:710-5.

11. Lekamwasam S, Trivedi DP, Khaw KT. An association between respiratory function and hip bone mineral density in older men: a cross-sectional study. Osteoporos Int. 2005;16:204-7.

12. Minghelli B, Nunes C, Oliveira R. Prevalence of overweight and obesity in portuguese adolescents: comparison of different anthropometric methods. North Am J Med Sci. 2013;5:653-9.

13. Moayyeri A. The association between physical activity and osteoporotic fractures: a review of the evidence and implications for future research. Ann Epidemiol. 2008;18(11):827-35.

14. Karlsson MK, Rosengren BE. Training and bone $\mathrm{V}$ from health to injury. Scand J Med Sci Sports. 2012;22:15-23.

15. Liphardt AM, Schipilow JD, Macdonald HM, Kan M, Zieger A, Boyd SK. Bone micro-architecture of elite alpine skiers is not reflected by bone mineral density. Osteoporos Int. 2015;26:2309-17.

16. Ackerman $\mathrm{K}$, Misra M. Bone Health In adolescent athletes with a focus on female athlete triad. Phys Sportsmed. 2011;39(1):131-41.

17. Kelly TL, Berger N, Richardson TL. DXA Body composition: theory and practice. Appl Radiat Isot. 1998:49:511-3.

18. Mirwald RL, Baxter-Jones AD, Bailey DA, Beunen GP. An assessment of maturity from anthropometric measurements. Med Sci Sports Exerc. 2002; 34(4):689-94,

19. Douma WR, van der Mark TW, Folgering HT. Mini-Wright peak flow meters are reliable after 5 years use. Eur Respir J. 1997;10:457-9.

20. Quanjer PH, Tammeling GJ, Cotes JE, Pedersen OF, Peslin R, Yernault JC. Lung volumes and forced ventilator flows; 1993 Update. Report working party "standardization of lung function tests", European coal and steel community, and European Respiratory Society. Eur Respir J 1993. 6(Suppl. 16):5-40.

21. Richards $L G$, Olson B, Palmiter-Thomas P. How forearm position affects grip strength. Am J Occup Ther. 1996;50(Suppl 2):133-8.

22. Tsuji S, Tsunoda N, Yata H, Katsukawa F, Onishi S, Yamazaki H. Relation between grip strength and radial bone mineral density in young athletes. Arch Phys Med Rehabil. 1995;76:234-8.

23. Ducher G, Jaffré C, Arlettaz A, Benhamou CL, Courteix D. Effects of longterm tennis playing on the muscle-bone relationship in the dominant and nondominant forearms. Can J Appl Physiol. 2005:30(1):3-17.

24. Baptista F, Barrigas C, Vieira F, Santa-Clara H, Homens PM, Fragoso I, Sardinha LB. The role of lean body mass and physical activity in bone health in children. J Bone Miner Metab. 2012;30(1):100-8.

25. Torres-Costoso A, Gracia-Marco L, Sánchez-López M, García-Prieto J, GarcíaHermoso A, Díez-Fernández A, Martínez-Vizcaíno V. Lean mass as a total mediator of the influence of muscular fitness on bone health in schoolchildren: a mediation analysis. J Sports Sci. 2014;33(8):817-30. https:// doi.org/10.1080/02640414.2014.964750.

26. Beverly MC, Rider TA, Evans MJ, Smith R. Local bone mineral response to brief exercise that stresses the skeleton. Br Med J. 1989;299:233-5.

27. Sandler RB, Cauley JA, Sashin D, Scialabba MA, Kriska AM. The effect of grip strength on radial bone in postmenopausal women. J Orthop Res. 1989;7:440-4.

28. Fried LP, Tangen CM, Walston J, Newman AB, Hirsch C, Gottdiener J, Seeman T, Tracy R, Kop WJ, Burke G, McBurnie MA. Cardiovascular Health Study Collaborative Research Group. Frailty in older adults: evidence for a phenotype. J Gerontol A Biol Sci Med Sci. 2001;56(3):M146-56.

29. Norman K, Stobäus N, Gonzalez MC, Schulzke JD, Pirlich M. Hand grip strength: outcome predictor and marker of nutritional status. Clin Nutr. 2011;30(2):135-42.

30. Frost HM. Bone's mechanostat: a 2003 update. Anatomical Record Part A Discoveries in Molecular, Cellular and Evolutionary Biology. 2003;275:1081101. 
31. Trost SG, Rosencrantz RR, Dzewaltowski D. Physical activity levels among children attending after school programs. Med Sci Sports Exerc. 2008;40: 622-9.

32. Campion JM, Maricic MJ. Osteoporosis in men. Am Fam Physician. 2003; 67(7):1521-6.

33. Conway SP, Oldroyd B, Brownlee KG, Wolfe SP, Truscott JG. A cross-sectional study of bone mineral density in children and adolescents attending a cystic fibrosis Centre. J Cyst Fibros. 2008;7:469-76.

34. Donadio M, Souza G, Tiecher G, Heinzmann-Filho JP, Paim TF, Hommerding PX, Marosti PJC. Bone mineral density, pulmonary function, chronological age, and age at diagnosis in children and adolescents with cystic fibrosis. J Pediatr. 2013;89(2):151-7.

35. Morin S, Leslie WD. Manitoba Bone Density Program. High bone mineral density is associated with high body mass index. Osteoporos Int. 2009;20(7): 1267-71.

36. Detter F, Nilsson JÅ, Karlsson C, Dencker M, Rosengren BE, Karlsson MK. A 3year school-based exercise intervention improves muscle strength - a prospective controlled population-based study in 223 children. BMC Musculoskelet Disord. 2014;15(1):353.

37. Ischander M, Zaldivar F Jr, Eliakim A, Nussbaum E, Dunton G, Leu SY, et al. Physical activity, growth, and inflammatory mediators in BMI-matched female adolescents. Med Sci Sports Exerc. 2007:39:1131-8.

38. Gracia-Marco L, Vicente-Rodriguez G, Casajus JA, Molnar D, Castillo MJ, Moreno LA. Effect of fitness and physical activity on bone mass in adolescents: the HELENA study. Eur J Appl Physiol. 2011;111:2671-80.

39. Fragoso CA, Gahbauer EA, Van Ness PH, Concato J, Gill TM. Peak expiratory flow as a predictor of subsequent disability and death in community-living older persons. J Am Geriatr Soc. 2008;56:1014-20.

40. Starr JM, Deary IJ, Whalley LJ. All-cause mortality in the Aberdeen 1921 birth cohort: effects of socio-demographic, physical and cognitive factors. BMC Public Health. 2008:8:307.

41. Sim Y, Lee JH, Kim Y, Chang JH. Association of Bone Mineral Density with airway obstruction and emphysema. Tuberc Respir Dis. 2012;72:310-7.

42. Vicente-Rodriguez G. How does exercise affect bone development during growth? Sports Med. 2006;36:561-9.

43. Sardinha LB, Baptista F, Ekelund U. Objectively measured physical activity and bone strength in 9-year-old boys and girls. Pediatrics. 2008;122:e728-36

44. Bandyopadhyay A, Basak AK, Tripathy S, Bandyopadhyay P. Peak expiratory flow rates in female brick-field workers of West Bengal. India Ergonomics SA. 2006;18(1):22-7.

\section{Submit your next manuscript to BioMed Central and we will help you at every step:}

- We accept pre-submission inquiries

- Our selector tool helps you to find the most relevant journal

- We provide round the clock customer support

- Convenient online submission

- Thorough peer review

- Inclusion in PubMed and all major indexing services

- Maximum visibility for your research

Submit your manuscript at www.biomedcentral.com/submit 